Erratum

\title{
Stance dependence of automatic postural adjustments in humans
}

\author{
J.M. Macpherson, F.B. Horak, D.C. Dunbar, and R.S. Dow \\ Exp Brain Res (1989) 78:557-566 \\ Due to a printers error, R.S. Dow was named as a co-author in the above article; this is not the case. The \\ footnote "Present address ..." applies to D.C. Dunbar.
}

\section{Announcements}

\section{Vienna Satellite Symposium on Sensory Neuropathies,}

\section{Vienna, Austria, September 22-23, 1990}

Joint meeting of the Austrian Muscular Dystrophy Association and the Austrian Societies for Neuroimmunology and Neuropathology.

This symposium is designed to give insight into particular properties of sensory neurons and their dysfunction in experimental and human diseases of sensory pathways. Leading experts will discuss recent developments and diagnostic methods.
For detailed information, please contact:

Frau Maurer

Wiener Medizinische Akademie

Alser Straße 4,

A-1090 Vienna, Austria

Telephone 222/43 1384/0, Telefax 222/42138323

First International Meeting on Brain and Immunity "Towards a novel therapeutic approach to psychoneuroendocrinimmune diseases", Sorrento Palace Congress Center, Sorrento, Italy, October 20-23, 1990

For information, please contact:

Jean Gilder Congressi sas

Via D. Fontana $134 / 8$

I-80128 Napoli, Italy

Telephone 39 (0) 815454617

International Congress "Stress and related disorders: from adaptation to dysfunction", Modena, Italy, November 18-21, 1990

Our aim is to achieve the largest multidisciplinary interaction on this important topic.

For detailed information, please contact:

Scientific Secretariat

Felice Petraglia (I)

Emilia Martignoni (I)

Dept. of Obstetrics and Gynecology,

University of Modena,

Via del Pozzo, 71

I-41100 Modena, Italy

Telephone 39-59-360253/379123 